\title{
Minor Shoulder Injury Reveals Spontaneous Regression of Proximal Humerus Osteochondroma
}

George Kalifis Sr. ${ }^{1}$, Theodorakys Marin Fermin Sr. ${ }^{2}$, Efstathios Konstantinou ${ }^{1}$, Vasilios Raoulis Sr. ${ }^{3}$, Michael Hantes Sr. ${ }^{1}$

\author{
1. Department of Orthopedic Surgery \& Musculoskeletal Trauma, University General Hospital of Larissa, Larissa, GRC \\ 2. Department of Traumatology, Hospital Universitario Periférico de Coche, Caracas, VEN 3. Emergency Department, \\ University General Hospital of Larissa, Larissa, GRC
}

Corresponding author: Vasilios Raoulis Sr., v_raoulis@yahoo.gr

\begin{abstract}
Osteochondromas are the most common benign bone tumor; nonetheless, the natural history is poorly understood as a result of the low threshold for resection and the fact that many of these lesions are asymptomatic and therefore never diagnosed. We present a case of a 17-year-old patient whose routine shoulder X-ray evaluation, due to a minor shoulder injury, revealed spontaneous regression of a previously documented left proximal humerus osteochondroma at six years follow-up. The likelihood of spontaneous regression should be better understood by orthopedic surgeons and taken into account in the decision process of whether to remove osteochondromas surgically or wait.
\end{abstract}

Categories: Pediatrics, Oncology, Orthopedics

Keywords: osteochondroma, spontaneous regression of osteochondroma, benign tumor shoulder, paediatric orthopedics, shoulder tumor

\section{Introduction}

Osteochondromas are bone tumors covered by cartilage, most frequently arising from the metaphyseal bone. The vast majority of these lesions are incidental findings, comprising $35 \%$ of all primary benign bone tumors [1]. Approximately $85 \%$ of osteochondromas are solitary lesions, while nearly $15 \%$ appear as multiple hereditary osteochondromas [2]. Despite being innocent, symptomatic lesions presenting with pain, neurovascular involvement, rapid progression, and malignant transformation may benefit from surgical intervention [1-3].

Review began 06/28/2021 Review ended 07/26/2021 Published 07/31/2021

\section{(๑) Copyright 2021}

Kalifis et al. This is an open access article distributed under the terms of the Creative Commons Attribution License CC-BY 4.0., which permits unrestricted use, distribution, and reproduction in any medium, provided the original author and source are credited.
Nevertheless, the literature is scarce regarding the natural history of solitary osteochondroma [4]. Recent studies evaluating long-term outcomes of conservative management of these lesions suggest that spontaneous regression of solitary osteochondromas may not be as rare as previously thought [4-6].

We present a case of a 17-year-old patient whose routine shoulder X-ray evaluation, due to a minor shoulder injury, revealed spontaneous regression of a previously documented left proximal humerus osteochondroma at six years follow-up.

\section{Case Presentation}

A 17-year-old male patient presented to our Emergency Department after two weeks of mild anterior shoulder ache of insidious onset, without a history of trauma, exacerbated by intense physical activity. Although the patient was barely symptomatic, he insisted on attending the Emergency Department being worried due to a history of a solitary osteochondroma of the left proximal humerus at the age of 11 years, which was decided to be left untreated.

Six years before, in March 2015, the patient was referred to our department after experiencing anterior shoulder pain for a month, mainly related to physical activity. A solid, tender, immobile palpable mass of the upper third of the anteromedial arm was found and documented. Absence of previous trauma, weight loss, night fever, or any other symptoms or signs suggesting malignancy were noted. Blood tests did not reveal any abnormality. The patient's neurovascular status was intact. The family history and past medical history of the patient were not contributory. X-ray evaluation showed a solitary sessile osteochondroma of the left proximal humerus (Figure 1). 


\section{Cureus}

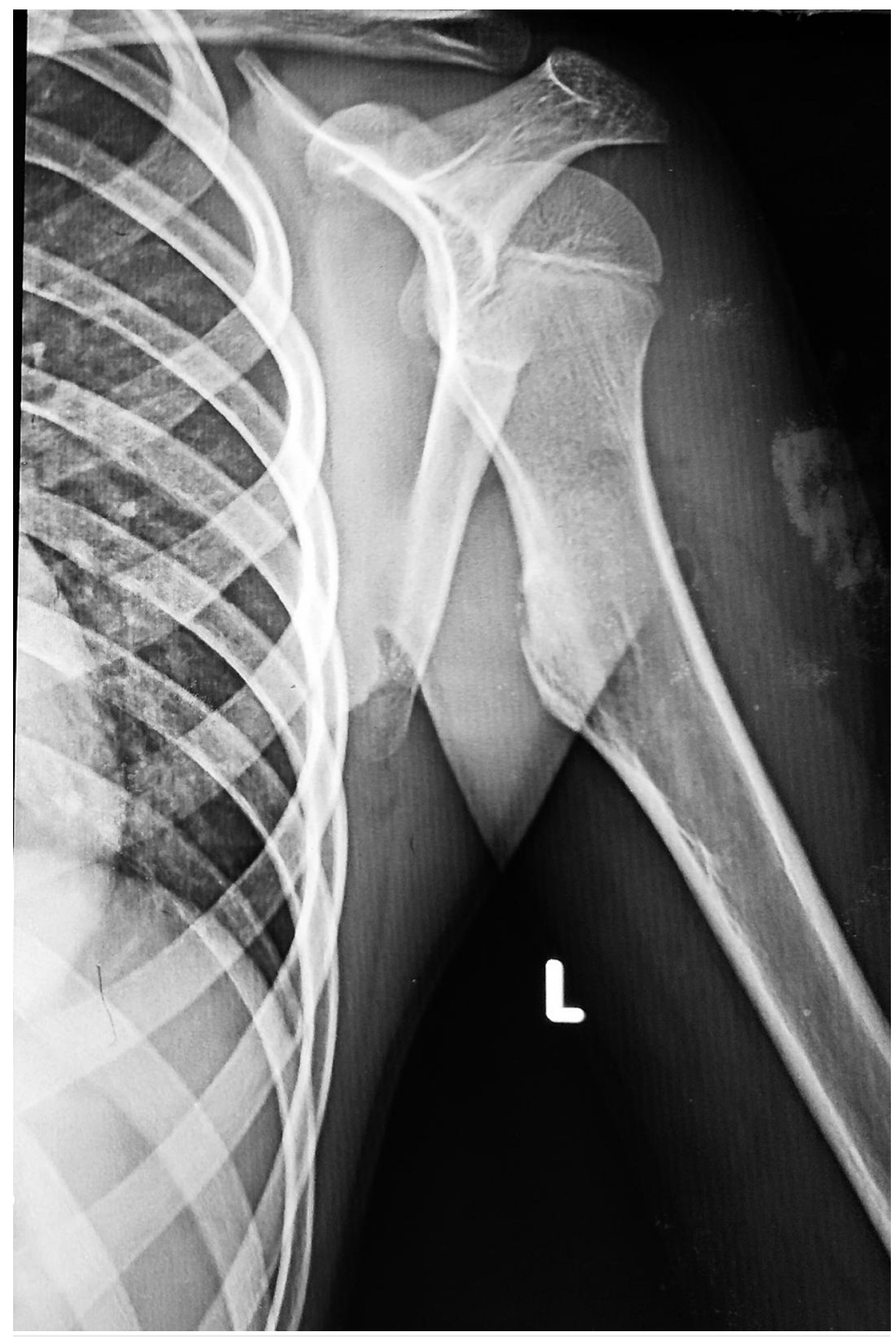

FIGURE 1: Left shoulder X-ray showing the presence of a sessile osteochondroma of the left proximal humerus at 11 years of age.

Magnetic resonance imaging (MRI) examination revealed a 4-cm triangular bone protuberance surrounded by a 4-mm cartilage cap, without enhancement after intravenous contrast agents administration (Figure 2). 


\section{Cureus}

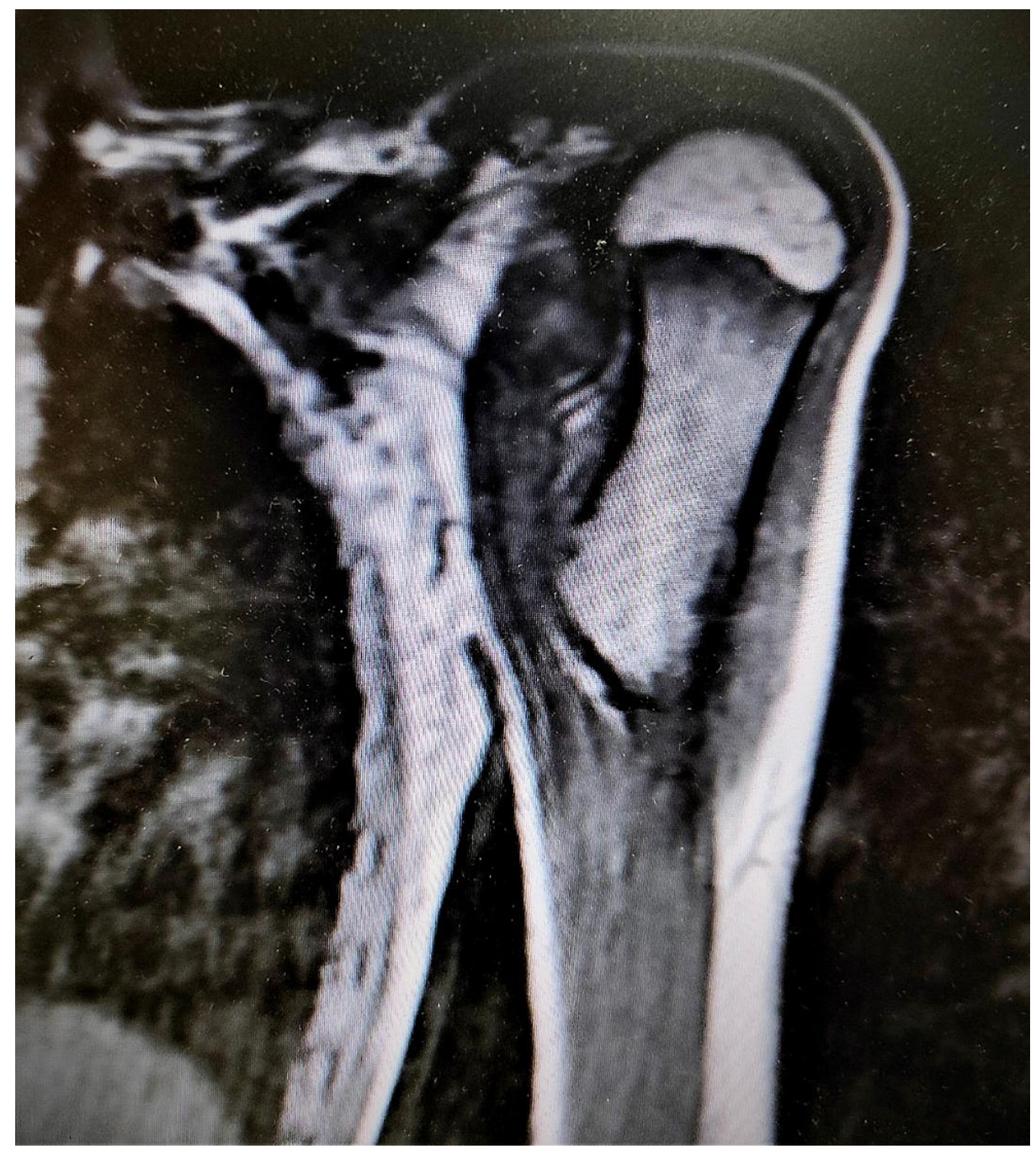

\section{FIGURE 2: Left shoulder MRI showing a 4-cm bony protuberance}

covered by a 4-mm cartilage cap (osteochondroma).

According to the Radiology Department's report, the lesion had features of an osteochondroma without malignant characteristics. However, imaging could not rule out a primary malignant bone tumor. The thorough clinical and radiographic evaluation did not show multiple hereditary exostoses. After explicitly discussing the treatment options with the patient and his family, an excisional biopsy was suggested. However, the patient's family refused to proceed to any intervention and did not return for follow-up.

During his Emergency Department attendance, physical examination of the left shoulder showed full range of motion (Flexion $=180^{\circ}$, Abduction $=180^{\circ}$, Extension $=40^{\circ}$, Internal rotation $=70^{\circ}$, External rotation $=$ $90^{\circ}$ ), equal to the uninvolved limb, without evidence of shoulder girdle muscle weakness (Muscle power 5/5). Functional assessment using patient reported outcome measures (PROMs) took place. Constant shoulder score stood at $96 / 100$, Oxford shoulder score stood at $46 / 48$. Also, the palpable mass that was documented during the past examination was not present. The patient's full neurovascular assessment was normal as well. The patient also mentioned that he is a recreational basketball player who started playing basketball three years ago without any limitations regarding his left shoulder. Surprisingly, plain X-rays of the left proximal humerus were normal (Figure 3). 


\section{Cureus}

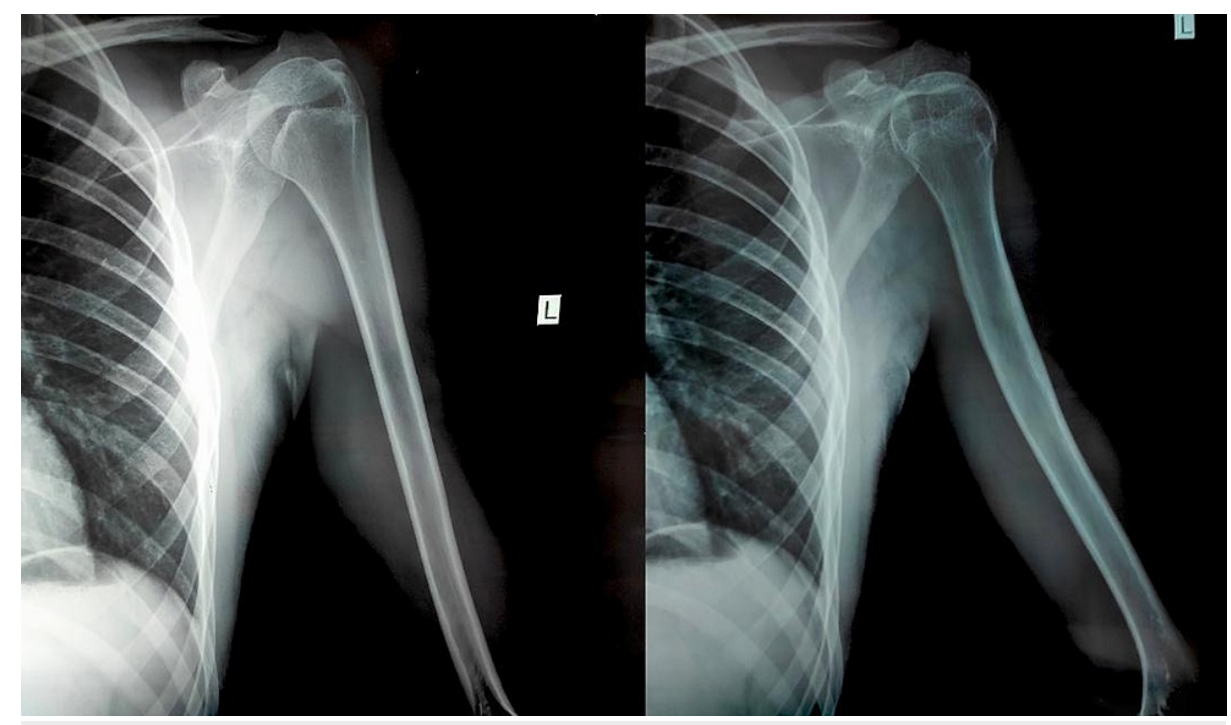

FIGURE 3: A routine shoulder X-ray due to minor injury shows incidental spontaneous regression of the proximal humerus osteochondroma at a six-year follow-up.

The previously documented osteochondroma had spontaneously regressed, and total remodeling of the bone was observed.

\section{Discussion}

The current case report presents the spontaneous regression of a left proximal humerus osteochondroma within six years of its initial diagnosis with plain radiographs and MRI confirmation. The most important feature of this case report is its late regression, as less than $1 \%$ of these rare entity regressions occur after 15 to 19 years of age [4].

The regression of solitary osteochondromas is a rare entity [3]. Many theories have been proposed to explain these regressions, like active resorption or metaphyseal remodeling [3-4,7-8]. In the present case, the progressive incorporation of the lesion in the cortex by positional growth of the adjacent bone seems the most plausible explanation.

The proximal humerus and the distal femur have the most reported regions of spontaneous regression of osteochondromas in the literature, presumably because of the higher incidence in these regions $[3,4,8]$. The lesions can appear either sessile or pedunculated, and some authors have theorized that it may play a role in the time for regression $[4,8]$. Claikens et al. reviewed 10 cases of resolving osteochondroma reported in the literature, seven were sessile, and three were pedunculated [9]. The age at diagnosis was limited to a range from 5 to 11 years, and resolution occurred before skeletal maturity was reached or within six years of initial diagnosis $[3,9]$.

A full-body examination is essential during the initial diagnosis to rule out multiple osteochondromas, especially in children up to 12 to 14 years of age [1]. The essential diagnostic tool is a plain radiograph, but an MRI examination of the affected area is critical for differential diagnosis and to predict the likelihood of malignancy [4]. Solitary, asymptomatic, and non-operated upper and lower limb lesions should be monitored using regular self-exam, clinical and radiographic control every two to three years. If growing of the lesion is noticed or MRI findings are unclear, biopsy or excision is indicated [10].

Osteochondroma excision, like any other surgical procedure, is not exempt from complications. Wirganowicz and Watts in a retrospective case series of 80 patients with 285 lesions, found a complication rate of a $12.5 \%$ in solitary osteochondromas. Peroneal neurapraxia was the most commonly observed complication (17.5\%) [11]. Other complications accounted for less than $1 \%$ and included arterial laceration, compartment syndrome, and fibular fracture.

An expectant approach of the asymptomatic or incidental lesions should be followed, especially in solitary sessile lesions up to the second decade of living, and when symptomatic, treated accordingly [4,8].

Education of the patient and family may play an essential role in managing these lesions, reducing the need for and risks of surgery [4]. Although the report of regressions in these lesions remains infrequent, the lack of a proper incidence limits the strength of any recommendation. 
The present case report is adding valuable information regarding natural history and management of humerus osteochondromas. In this case the patient denied undergoing surgical excision and lost follow-up. Consequently, spontaneous regression was the outcome of non-proposed conservative treatment at a sixyear follow-up. Educationally, our case may prove helpful because: The final outcome (although incidental) was good despite the initial suggestion of the surgeon; may highlight the role of conservative treatment of proximal humerus osteochondromas at a long-term follow-up; may provide useful data for further evidencebased research.

A limitation to this study is the lack of histopathological confirmation, but the MRI characterization of the present lesion was strong enough to support the diagnosis. Another limitation was the lack of full body examination.

\section{Conclusions}

In conclusion, regression of solitary osteochondromas remains under-reported and under-diagnosed. The expectant approach is advisable during the first two decades of living, as spontaneous regression may still be feasible.

\section{Additional Information \\ Disclosures}

Human subjects: Consent was obtained or waived by all participants in this study. Conflicts of interest: In compliance with the ICMJE uniform disclosure form, all authors declare the following: Payment/services info: All authors have declared that no financial support was received from any organization for the submitted work. Financial relationships: All authors have declared that they have no financial relationships at present or within the previous three years with any organizations that might have an interest in the submitted work. Other relationships: All authors have declared that there are no other relationships or activities that could appear to have influenced the submitted work.

\section{References}

1. Kitsoulis P, Galani V, Stefanaki K, Paraskevas G, Karatzias G, Agnantis NJ, Bai M: Osteochondromas: review of the clinical, radiological and pathological features. In Vivo. 2008, 22:633-646.

2. Murphey MD, Choi JJ, Kransdorf MJ, Flemming DJ, Gannon FH: Imaging of osteochondroma: variants and complications with radiologic-pathologic correlation. Radiographics. 2000, 20:1407-1434. 10.1148/radiographics.20.5.g00se171407

3. Heyworth PB, Rashid M: Regression of a solitary osteochondroma of the distal humerus in a toddler following trauma. Radiol Case Rep. 2019, 14:187-189. 10.1016/j.radcr.2018.10.006

4. Arkader A, Dormans JP, Gaugler R, Davidson RS: Spontaneous regression of solitary osteochondroma: reconsidering our approach. Clin Orthop Relat Res. 2007, 460:253-257. 10.1097/BLO.0b013e3180479789

5. Aiba H, Yamada S, Yamamoto N, Hayashi K, Miwa S, Tsuchiya H, Otsuka T: Spontaneous shrinkage of solitary osteochondromas. Skeletal Radiol. 2018, 47:61-68. 10.1007/s00256-017-2760-0

6. Collier CD, Nelson GB, Conry KT, Kosmas C, Getty PJ, Liu RW: The natural history of benign bone tumors of the extremities in asymptomatic children: a longitudinal radiographic study. J Bone Joint Surg Am. 2021, 103:575-580. 10.2106/JBJS.20.00999

7. Paling MR: The "disappearing" osteochondroma. Skeletal Radiol. 1983, 10:40-42. 10.1007/BF00355391

8. Passanise AM, Mehlman CT, Wall EJ, Dieterle JP: Radiographic evidence of regression of a solitary osteochondroma: a report of 4 cases and a literature review. J Pediatr Orthop. 2011, 31:312-316. 10.1097/BPO.0b013e31820fc676

9. Claikens B, Brys P, Samson I, Baert AL: Spontaneous resolution of a solitary osteochondroma . Skeletal Radiol. 1998, 27:53-55. 10.1007/s002560050338

10. Herget GW, Kontny U, Saueressig U, et al.: Osteochondroma and multiple osteochondromas: recommendations on the diagnostics and follow-up with special consideration to the occurrence of secondary chondrosarcoma. Radiologe. 2013, 53:1125-1136. 10.1007/s00117-013-2571-9

11. Wirganowicz PZ, Watts HG: Surgical risk for elective excision of benign exostoses . J Pediatr Orthop. 1997, $17: 455-459$. 